\title{
In situ Environmental HRTEM Discloses Low Temperature Carbon Soot Oxidation by Ceria-zirconia at Nanoscale
}

\author{
Mimoun Aouine, ${ }^{a}$ Eleonora Aneggi, ${ }^{b}$ Jordi Llorca, ${ }^{c}$ Alessandro Trovarelli, ${ }^{b}$ Philippe Vernoux ${ }^{a}$
}

\begin{abstract}
The very close contact between ceria-zirconia and carbon soot allows detection of oxygen transfer from ceria-zirconia to carbon by in situ Environmental HRTEM already at low temperatures. This highlights the outstanding redox behavior and soot oxidation potential of ceria-zirconia when suitable carbon-catalyst arrangements are generated at nanoscale.
\end{abstract}

Carbon soot oxidation is one of the most important functions of a diesel exhaust aftertreatment system; under oxygen containing atmosphere it generally requires temperatures above $600^{\circ} \mathrm{C}$, and the use of a catalyst is mandatory to lower the onset temperature for combustion. Thus, looking for active and robust carbon soot oxidation catalysts is a priority in the development of compact and efficient exhaust aftertreatment systems for diesel engines. Ceria has become one of the most interesting materials in catalysis due to the combination of several effects including its unsurpassed ability to release and uptake oxygen while maintaining structural stability ${ }^{1}$. For these reasons, ceria-based materials, and particularly $\mathrm{CeO}_{2}-\mathrm{ZrO}_{2}$ solid solutions, have a great soot oxidation potential and over the last years a large number of studies have investigated the behavior and the role of $\mathrm{CeO}_{2}$ in this complex reaction environment, where both catalyst and carbon are in solid phase ${ }^{2-4}$. The mechanism of carbon soot oxidation over $\mathrm{CeO}_{2}$ goes through the formation of oxygen vacancies at the interface between catalyst and carbon which then act as sites for activation of oxygen with formation of peroxide and superoxide species which spill over the soot surface to oxidize carbon atoms ${ }^{5,6}$. This mechanism deeply relies on the degree of contact between $\mathrm{CeO}_{2}$ and carbon because this affects both the vacancy formation at the interface, where carbon acts as reductant for ceria, and the spilling of active oxygen species, which need a large contact area to display their oxidation potential. Therefore, it is of great importance to investigate the morphology of catalyst and carbon contact at nanoscale, to highlight the promotion of soot oxidation in the interfacial region ${ }^{7,8}$. We recently reported that the high degree of contact achieved by high-energy milling of $\mathrm{CeO}_{2}-\mathrm{ZrO}_{2}$ and carbon resulted in the formation of a narrow layer of carbon displaying a large interface with $\mathrm{CeO}_{2}$ at nanoscale increasing the number of contact points and boosting soot oxidation rate to low temperatures ${ }^{9}$. Here, we use in situ environmental transmission electron microscopy to look at nanoscale for the first time the outstanding soot oxidation potential at low temperatures of ceria-

\footnotetext{
a. Institut de Recherches sur la Catalyse et l'Environnement de Lyon, CNRS, Université Claude Bernard Lyon 1, Villeurbanne, France Address here.

b. Dipartimento Politecnico, Università degli Studi di Udine, and INSTM, via del Cotonificio 108, 33100 Udine, Italy.

c. Institute of Energy Technologies, Department of Chemical Engineering and Barcelona Research Centre in Multiscale Science and Engineering, Universitat Politècnica de Catalunya, 08019, Barcelona, Spain.
}

zirconia in the above configuration. It is shown that the creation of a "supertight" contact at nanoscale between soot and catalyst activates oxygen transfer already at room temperature; in contrast, the same catalyst under loose contact conditions, requires temperatures close to $500^{\circ} \mathrm{C}$ to start burning soot. This is a further piece of evidence in favor of the important role of active oxygen species in low temperature oxidation and confirms the need of a large ceria-soot contact area for this active species to display their oxidation potential.

Two samples of $\mathrm{Ce}_{0.8} \mathrm{Zr}_{0.2} \mathrm{O}_{2}$ (CZ80) solid solutions with a different degree of contact between carbon and catalyst were investigated. The synthesis and the characteristics of the starting CZ80 material are summarized in the supporting information (Figures $1 S$ and $2 S$ and Table 1S). In one sample, the contact is achieved by gently mixing with a spatula the catalyst and carbon, in the so called "loose contact mode". These conditions, that are more representative of the real application, are characterized by the presence of bigger soot particles mixed with the oxide catalyst with a poor degree of contact (Figure 3S). On the opposite, in the second sample, to achieve a high contact area, the catalyst and carbon soot were put in contact in a high energy mill for a period of $8 \mathrm{~h}^{9}$. This allows the formation of a morphology were thin carbon layers and small soot particles surround ceria-zirconia crystallites (Figure 3S). This configuration is characterized by the absence of large carbon particles and contact area is optimized at nanoscale level. Although this configuration is not representative of the real condition, the robust contact generated can offer a way to disclose important characteristic of carbon-ceria interaction that cannot be detected when contact is achieved by the usual methodology. Figure 1 shows the carbon oxidation profiles in the two contact configurations as measured in a temperature programmed oxidation mode. Carbon in loose sample is oxidized to $\mathrm{CO}_{2}$ at higher temperature, with a maximum at ca. $550^{\circ} \mathrm{C}$ and a small unresolved peak at $630^{\circ} \mathrm{C}$, likely due to some carbon not in contact with $\mathrm{Ce}_{0.8} \mathrm{Zr}_{0.2} \mathrm{O}_{2}$ that typically burns at a temperature of ca. $650^{\circ} \mathrm{C}^{10}$. Sample after milling shows $\mathrm{CO}_{2}$ formation with a maximum at ca. $275^{\circ} \mathrm{C}$. The onset of oxidation is observed at relatively low temperature, indicating that under these conditions, active oxygen species can be formed and are active already in the range $50-150^{\circ} \mathrm{C}$. In order to evaluate the specific effect of milling, a sample of $\mathrm{Ce}_{0.8} \mathrm{Zr}_{0.2} \mathrm{O}_{2}$ was initially milled for $8 \mathrm{~h}$ and then mixed with carbon soot under conventional loose conditions. The oxidation temperatures in this case do not differ from those observed for $\mathrm{Ce}_{0.8} \mathrm{Zr}_{0.2} \mathrm{O}_{2}$ in loose contact mode, indicating that the milling of ceria-zirconia solid solution does not induce any modification in the material that can be responsible for the promotion of the oxidation behaviour. The lack of material modifications after milling comes also from the XP profile of $\mathrm{Ce} 3 \mathrm{~d}$ and $\mathrm{Zr} 3 \mathrm{p}$ photoelectrons in bare $\mathrm{Ce}_{0.8} \mathrm{Zr}_{0.2} \mathrm{O}_{2}$ which does not show 
changes before and after milling (Figure 4S). The promotion of soot oxidation is only observed when soot and catalyst are milled together, indicating a strong interaction between the two species with creation of an extremely reactive interface and large structural disorder of carbon (Figure 5S). Soot oxidation process was followed in situ by using a latest generation ETEM (Titan 80-300 kV from FEI ${ }^{\mathrm{TM}}$ ) equipped with an aberration corrector between room temperature and $550^{\circ} \mathrm{C}$, both in the presence and absence of oxygen. A preliminary observation has confirmed the stability of the small CZ80 crystallites under the electron beam (Figure 6S, video 1). Characterization of the soot-CZ80 loose contact mixture was first performed at room temperature with $1 \mathrm{mbar}$ of $\mathrm{O}_{2}$ in the ETEM.

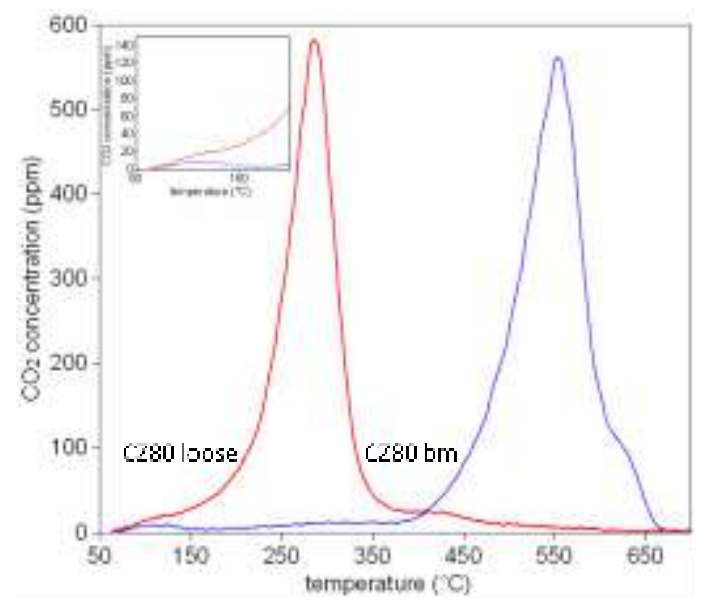

Figure 1: Temperature programmed oxidation profiles of $\mathrm{CO}_{2}$ evolved from CZ80/C mixtures under loose contact (blue curve) and under supertight contact (red curve). In the inset, carbon dioxide production in the low temperature range is shown, indicating that the onset of reaction in the presence of air is located as low as 50$150{ }^{\circ} \mathrm{C}$ for the sample with contact achieved by milling.

Figure 2 (a-c) and video 2 show that a soot grape (in light grey) in poor contact with CZ80 crystallites (in dark) is not oxidized by the oxygen even after $20 \mathrm{~s}$ under the electron beam at RT. The temperature of the sample was raised up to $550^{\circ} \mathrm{C}$ to investigate the reactivity of these big soot particles. From $500^{\circ} \mathrm{C}$ (Figure 2 (d-f) and video 3 ), soot grapes start to be slowly oxidized mainly at the contact points with CZ80 crystallites in good agreement with previous similar ETEM observations ${ }^{11}, 12$. The soot oxidation rate at the catalyst interface is much higher at $550^{\circ} \mathrm{C}$ (video 3 ) in excellent agreement with TPO profiles (Figure 1) that show a maximum at $550^{\circ} \mathrm{C}$. The lower oxygen partial pressure used in the ETEM ( 1 mbar) compared to TPO measurements ( $100 \mathrm{mbar}$ ) is most probably counter-balanced by the electron beam effect. Thin carbon layers were observed on samples after milling and were found to be stable under the electron beam at RT under ultra high vacuum (Figure 3 , video 4 ). A low oxygen partial pressure $(0.37 \mathrm{mbar})$ was then introduced in the ETEM at RT. Figure 4 and video 5 clearly demonstrate that the carbon layers can be already oxidized from room temperature in contact with CZ80 crystallites. TEM images highlight the presence of isolated CZ80 nanoparticles embedded into carbon globules (Figure 4, video 5 and 6 , Figure 7S), most probably due to the high energy milling. This strongly increases the contact area between the catalyst and the soot.

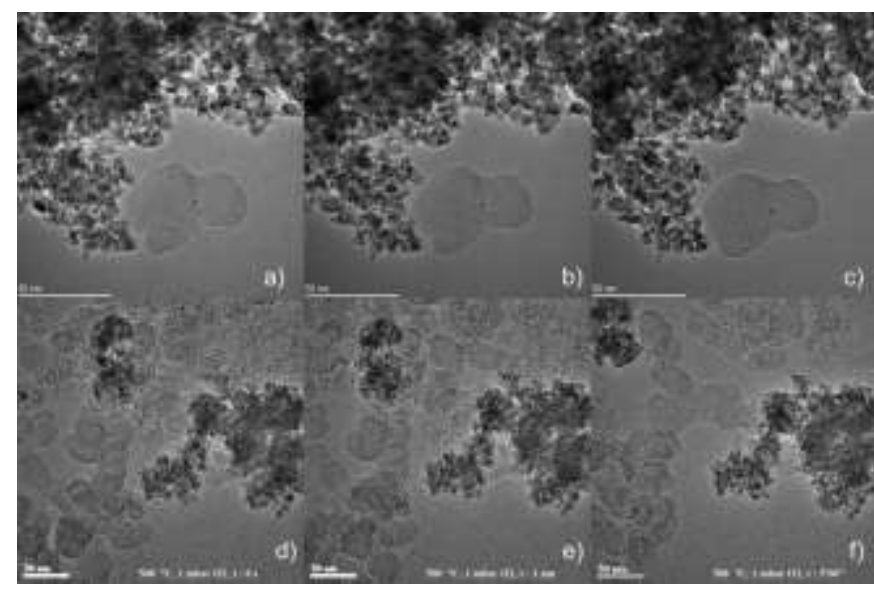

Figure 2: ETEM images of CZ80/C mixture in loose contact mode extracted from video 2 recorded under $1 \mathrm{mbar}$ of $\mathrm{O}_{2}$ at RT with a beam voltage $=300 \mathrm{kV}$; a) starting time t0, b) to $+10 \mathrm{~s}, \mathrm{c}$ ) to $+20 \mathrm{~s}$; ETEM images extracted from video 3 recorded under 1 mbar of $\mathrm{O}_{2}$ at $500^{\circ} \mathrm{C}$ with a beam voltage $=300 \mathrm{kV}$; d) starting time to, e) to $+60 \mathrm{~s}, \mathrm{f}$ ) to +300 s.

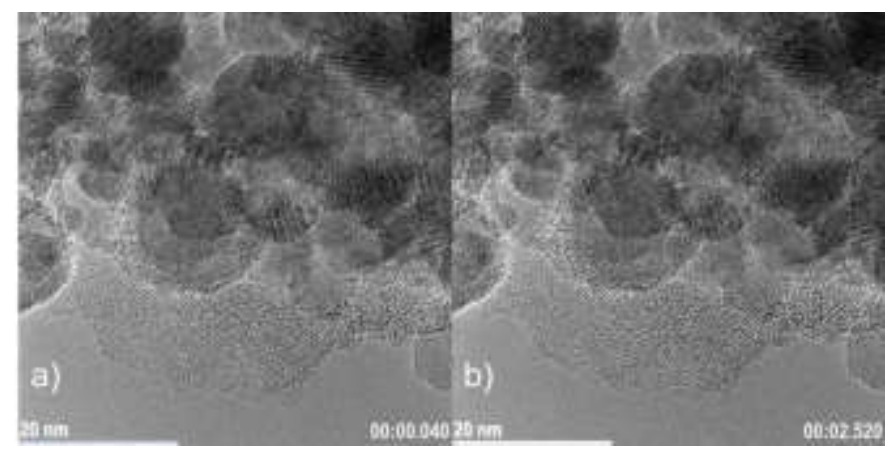

Figure 3: ETEM images extracted from video 4 recorded under UHV at RT. Beam voltage $=300 \mathrm{kV}$; a) starting time t0, b) t0 $+2.5 \mathrm{~s}$. CZ80/C mixture after $8 \mathrm{~h}$ milling.

As shown in videos 5 and 6 , these CZ80 nanoparticles, surrounded with a colored circle on Figure 4 and 75 , are moving with the carbon globules which can be gradually consumed at various contact points. The observed temperature shift between in-situ ETEM oxidation at room temperature and TPO experiments (where oxidation starts at around $50-100^{\circ} \mathrm{C}$ ) can be explained by an enhanced production of active oxygen species with CZ80 under the electron beam at low temperature. This likely occurs through formation of oxygen vacancies mainly at the carbon ceria-zirconia interface which then promote reaction with gas phase oxygen to form active superoxide species $^{5}$.

In summary, the unprecedented low temperature oxidation of carbon soot by ceria-zirconia in a so called "supertight" contact mode has been shown to occur at nanoscale level. Although this type of contact is not typical of the real conditions, it might help understanding the low temperature behavior of ceria-based catalysts, and particularly the ability of ceria to activate oxygen at low temperature with the help of unique arrangements at nanoscale. More generally, this shows that the building of an appropriate interface at nanoscale can result in unexpected chemical functionalities. 


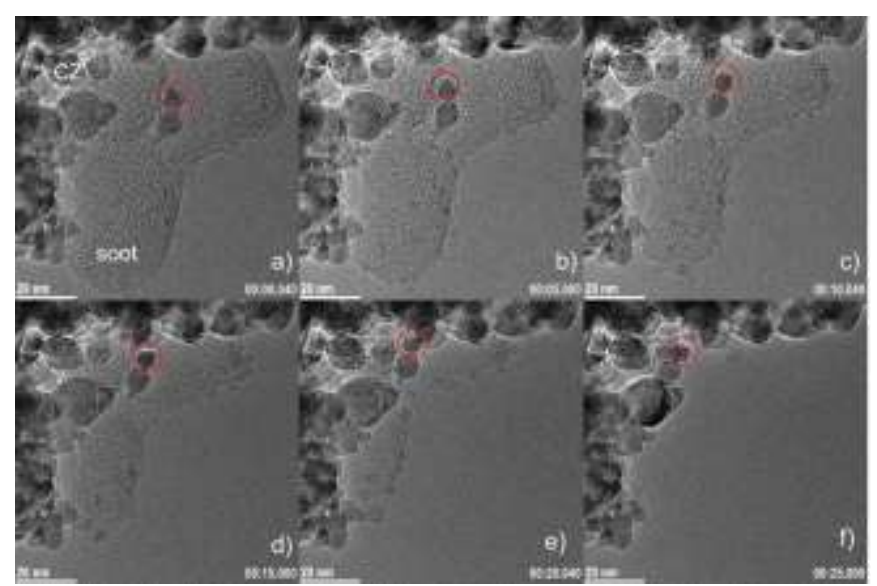

Figure 4: ETEM images extracted from video 5 recorded under 0.37 mbar of $\mathrm{O}_{2}$ at room temperature. Beam voltage: $300 \mathrm{kV}$; a) starting time to, b) to $+5 \mathrm{~s}, \mathrm{c})$ t0 $+10 \mathrm{~s}, \mathrm{~d}$ ) t0 $+15 \mathrm{~s}$, e) t0 $+20 \mathrm{~s}$ and f) t0 $+25 \mathrm{~s}$. $\mathrm{CZ80} / \mathrm{C}$ mixture after $8 \mathrm{~h}$ of milling.

Acknowledgements: thanks are due to the CLYM (www.clym.fr) for its guidance in the ETEM project, which was financially supported by the CNRS, the Region Rhône-Alpes, the 'GrandLyon' and the French Ministry of Research and Higher Education. A.T. thanks Interreg V Italy-Austria project Coat4Cata (project n. ITAT 1019). J.L. is Serra Húnter Fellow and is grateful to ICREA Academia program and grants MINECO/FEDER ENE2015-63969-R and GC 2017 SGR 128.

\section{Notes and references}

1 T. Montini, M. Melchionna, M. Monai and P. Fornasiero, Chem. Rev., 2016, 116, 5987-6041.

2 A. Bueno-Lopez, Appl Catal B-Environ, 2014, 146, 1-11.

3 E. Aneggi, C. d. Leitenburg and A. Trovarelli, in Catalysis by Ceria and Related Materials, 2nd Edition, eds. A. Trovarelli and P. Fornasiero, Imperial College Press, London, 2013, DOI: doi:10.1142/9781848169647_0011, pp. 565-621.

4 M. Piumetti, S. Bensaid, N. Russo, D. Fino, Appl Catal BEnviron, 2016, 180, 271-282.

5 L. Soler, A. Casanovas, C. Escudero, V. Perez-Dieste, E. Aneggi, A. Trovarelli and J. Llorca, Chemcatchem, 2016, 8, 2748-2751.

6 M. Machida, Y. Murata, K. Kishikawa, D. J. Zhang and K. Ikeue, Chem Mater, 2008, 20, 4489-4494.

7 E. Aneggi, D. Wiater, C. de Leitenburg, J. Llorca and A. Trovarelli, Acs Catal, 2014, 4, 172-181.

8 Y. C. Wei, J. Q. Jiao, X. D. Zhang, B. F. Jin, Z. Zhao, J. Xiong, Y. Z. Li, J. Liu and J. M. Li, Nanoscale, 2017, 9, 4558-4571.

9 E. Aneggi, V. Rico-Perez, C. de Leitenburg, S. Maschio, L. Soler, J. Llorca and A. Trovarelli, Angew Chem Int Edit, 2015, 54, 14040-14043.

10 J. M. Christensen, J. D. Grunwaldt and A. D. Jensen, Appl Catal B-Environ, 2016, 188, 235-244.

11 S. B. Simonsen, S. Dahl, E. Johnson and S. Helveg, J Catal, 2008, 255, 1-5.

12 A. Serve, T. Epicier, M. Aouine, F. J. C. S. Aires, E. Obeid, M. Tsampas, K. Pajot and P. Vernoux, Appl Catal A-Gen, 2015, 504, 74-80. 